\title{
Study of Oxidation of Some Alpha Amino Acids by 1, 3-Dichloro- 5, 5-Dimethylhydantoin in Aqueous Acetic Acid Medium
}

\author{
Shweta Neeraj ${ }^{1}$, S. S. Parihar ${ }^{1}$ and A.P. Dwivedi ${ }^{2}$ \\ ${ }^{1}$ Department of Chemistry, Govt. Girls P. G. College, Rewa-486001 (M.P.) India \\ ${ }^{2}$ Department of chemistry, Govt. Sanjay Gandhi Smrati Auto., P.G., College Sidhi M.P India
}

*Corresponding Author: Shweta Neeraj, Department of Chemistry, Govt. Girls P. G. College, Rewa486001 (M.P.) India

\begin{abstract}
The mechanistic kinetic studies of oxidation of $\ell$-Alanine and $\ell$-Glycine by 1,3-dichloro-5, 5dimethylhydantoin (DCDMH) in aqueous acetic acid medium in presence of $\mathrm{H}^{+}$ions have been performed. The $r$ ate of reaction is proportional to the first power of concentration of $A A$ and DCDMH. The rate of reaction is enhanced by the increasing $\left[\mathrm{H}^{+}\right]$and percentage of acetic acid. The main product of the oxidation is corresponding aldehydes. $\mathrm{H}_{2} \mathrm{O}^{+} \mathrm{Cl}$ has been assumed as prime reacting oxidizing species and proposed mechanism ruled out the involvement of free radicals. The thermodynamic parameters for the oxidation have been computed in the slow step of mechanism. The derived rate law was in good conformity with the mechanism.
\end{abstract}

Keywords: Conformity, proportional, deamination, consistent, prime.

\section{INTRODUCTION}

1,3-dichloro-5,5-dimethylhydantoin (DCDMH) belongs to the class of $\mathrm{N}$-halo compounds and is a moderate oxidant. The final hydrolysis of this compound leads to the formation of active positive halogen species like $\mathrm{HOCl}$ and $\mathrm{H}_{2} \mathrm{O}^{+} \mathrm{Cl}$. The $\mathrm{H}_{2} \mathrm{O}^{+} \mathrm{Cl}$ manifests more in non-polar or less polar media, extensively used as a chlorinating and oxidizing agents in organic substrates. The generated species are utilized in solution and gaining importance in organic synthesis and also in analytical determination of organic compounds. ${ }^{\mathbf{1 , 2}}$ Since the N-halooxidants exhibit appreciable stability both in acid and alkaline medium ${ }^{3,4}$ hence widely used in kinetic studies. Biological production of hypochlorous acid $(\mathrm{HOCl})$ is also reported during activation of ecosinophilis. The $\mathrm{H}_{2} \mathrm{O}^{+} \mathrm{Cl}$ and $\mathrm{HOCl}$ thus produced kill the invading pathogens and also play an important role in damaging the tissues. It was also concluded that alphaaminoacids namely $\ell$-Alanine and $\ell$-Glycine are the major biological compounds ${ }^{5}$ reacting with the $\mathrm{H}_{2} \mathrm{O}^{+} \mathrm{Cl}$.

Although a lot of works on the oxidation of amino acids have been reported by $\mathrm{N}$-halo oxidants. ${ }^{6-12}$. The survey of literature reveal that involving DCDMH a limited application reports ${ }^{13-15}$ on oxidation of chalcones ${ }^{16}$, D-glucose and D-fructose ${ }^{17}$ are available. It is to be noted that no systematic kinetic study was investigated on oxidation of $\ell$-Alanine and $\ell$-Glycine by 1,3-dichloro-5, 5-dimethylhydantoin.

\section{EXPERIMENTAL}

All the reagents used were of A.R. grade and the solutions were prepared in double distilled water. DCDMH, Acros brand was used. Standard solution of DCDMH was prepared afresh just before the reactions were carried out. All the reactions were performed in the thermostat and temperature was maintained at $\pm 0.1^{0} \mathrm{C}$.

The reaction was initiated under pseudo-first order condition [AA] $>$ [DCDMH]. The reaction mixture was homogeneous throughout the course of the reaction. The reaction rate was found estimating, the amount of the unconsumed DCDMH iodometrically upto $80 \%$ complication of the reaction. The pseudo-first order rate constants $\left[\mathrm{k}_{\mathrm{obs}}\right]$ were determined from the slopes of linear plots of $\log (\mathrm{a}-\mathrm{x})$ versus time. The replicate runs showed that the velocity constant for the reactions understudy were reproducible within $\pm 3 \%$. 


\section{RESULTS AND DISCUSSION}

The stoichiometry of the reaction mixtures containing varying [DCDMH] at different quantities of AA at constant concentrations of $\mathrm{H}^{+}$ions was determined by several sets of experiments at their required temperatures. The whole mixture were allowed to react for 24 hours in thermostat and then analysed the reaction. The unconsumed DCDMH remaining was estimated iodometrically.

After completion of the reaction showed 1:1 (AA: DCDMH) stoichiometry. The oxidation products were identified as aldehydes and 5,5-dimethylhydantoin, by their spot test. The main products of oxidation were confirmed by chemical and chromatographic methods and compared with those of the standard samples. The effect of varying [DCDMH] five-fold was examined by maintaining all other concentration of the reactants at constant temperature and fixed percentage of acetic acid. The values of rate constant were found to be constant, indicating first-order dependence of rate on [DCDMH] as evaluated from the slope of plots $(\log (a-x)$ vs. time).

The kinetic study was performed at several initial concentration of the amino acids at constant $[\mathrm{DCDMH}],\left[\mathrm{H}^{+}\right]$and fixed percentage of acetic acid and temperature. The first-order rate constants were found to increase linearly with increase in [AA] (Table 1). The plot (Fig. 1) of k versus [AA] and 1/k versus 1/ [AA] (Fig.2) are linear passing through the origin with unit slope showing first-order kinetics with respect to $[\mathrm{AA}]$. The reaction rate measured with various $\left[\mathrm{H}^{+}\right]$was found to accelerate with increasing $\left[\mathrm{H}^{+}\right]$ion. The order of the reaction with respect to $\left[\mathrm{H}^{+}\right]$ion is unity. Overall reaction was acid catalysed. It was also confirmed from the plot of $\log \mathrm{k}$ against $\log \left[\mathrm{H}^{+}\right]$. The rate of oxidation increases moderately with increase in the percentage of acetic acid, that is, in increasing dielectric constant of the medium (Table 2). A plot (Fig.3) of log $\mathrm{k}$ versus 1/ D is linear with positive slope indicating a dipole type of interaction.

The addition of primary salts do not affect the rate of oxidation whereas added catalyst of varying $\left[\mathrm{Cu}^{++}\right]$ions shows an accelerating effect in the reaction velocity. The study clearly rules out the formation of free radicals when reaction mixture was tested with acrylonitrile monomer. ${ }^{18}$ The rate of reaction decreases with the addition of various concentration of [DMH], a reductant product of reaction. The inverse plot of $\mathrm{k}$ versus $\mathrm{DMH}$ is obtained linear with positive slope. $\mathrm{The}^{\mathrm{H}} \mathrm{O}_{2}^{+} \mathrm{Cl}$ have been postulated as a prime reacting species based on experimental results that participates in commencing the oxidation reaction.

\section{MeChANiSM}

The $\ell$-amino acids form Zwitter ions and halo oxidant 1,3-dichloro-5, 5-dimethyl hydantoin $[\mathrm{DCDMH}]$ on hydrolysis yields finally dimethylhydantoin $\mathrm{DMH}$ in aqueous solution. The following equilibrium exists:
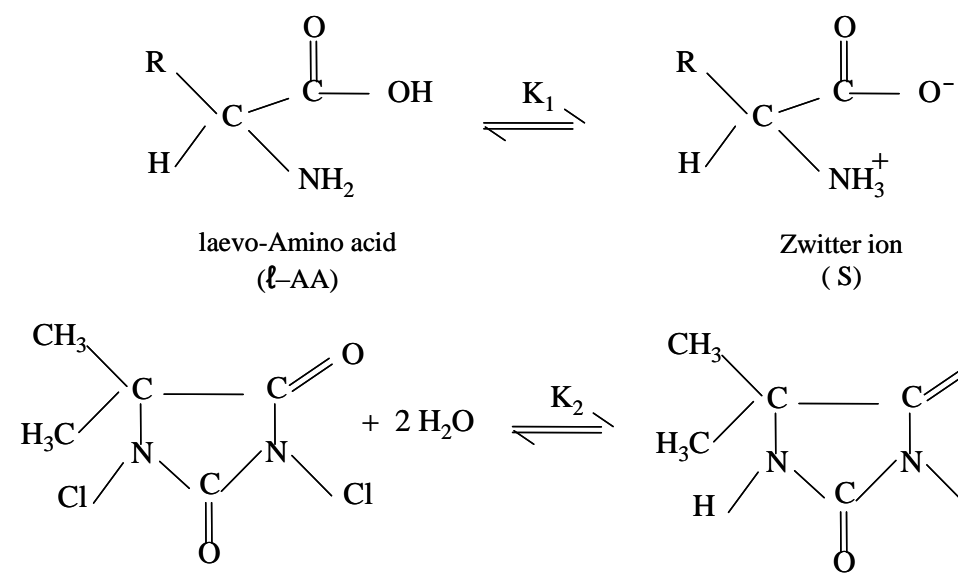

1,3- dichloro-5, 5-dimethyl hydantoin (DCDMH)<smiles>CC1NC(=O)NC1(C)C</smiles>

$$
\mathrm{HOCl}+\mathrm{H}^{+} \rightleftharpoons \stackrel{\mathrm{K}_{3}}{\rightleftharpoons} \underset{\text { (Protonated) }}{\mathrm{H}_{2} \mathrm{OCl}^{+}}
$$




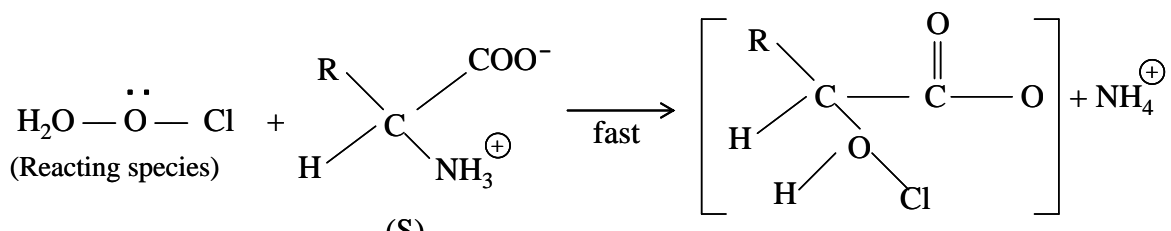

(S)
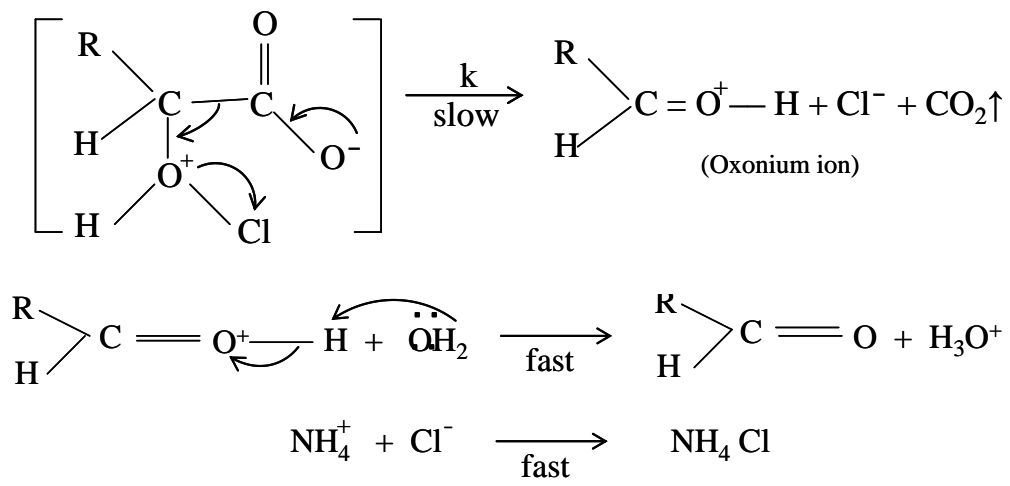

where, $\mathrm{R}=-\mathrm{H}$ and $-\mathrm{CH}_{3}$ for corresponding aldehydes.

The relevant rate law based on mechanism is represented by equation (8).

$$
\frac{-\mathrm{d}}{\mathrm{dt}}[\mathrm{DCDMH}]=\frac{\mathrm{k} \mathrm{K}_{1} \mathrm{~K}_{2} \mathrm{~K}_{3}[\mathrm{~S}]\left[\mathrm{H}^{+}\right]}{[\mathrm{DMH}]+\mathrm{K}_{2}}
$$

The rate law clearly points out the observed kinetic features. The order of reactivity is found in the following sequence:

$$
\ell \text {-Glycine }>\ell \text {-Alanine }
$$

The above order of reactivity is due to deamination of an alanine and glycine molecule produces a stable alkyl free radical $\mathrm{CH}_{3} \mathrm{COO}$, which can be induced in a solid or aqueous alanine by radiation at neutral $\mathrm{pH}$. The similar mechanism has also been supported by Mamta et al. ${ }^{19}$ for the oxidation study of amino acid by halo- oxidant.

The influence of electrophilic $\mathrm{H}_{2} \mathrm{O}^{+} \mathrm{Cl}$ in presence of acid, a new bond is formed by a proton. The electron deficient species is formed at the transition state which is stabilized by inductive effect pushing driving force towards a bond, sufficient to cleavage and eliminating proton ultimately resulting the products. The complex formed at the transition states is momentary not rigid being unstable, intermediate complex immediately decomposes in rate determining step to give the final products such as acetaldehyde and formaldehyde respectively.

The above order of reactivity was also supported by the Arrhenius parameters controlling the reaction rate. The nature of the short lived transition state is the same for to the substrates studied by the order of observed entropy of activation.

\section{CONCLUSION}

Dichlorodimethylhydantoin (DCDMH) has been found as a moderate oxidant for the oxidation of $\ell$ Amino acids. The thermodynamic and activation parameters determined are well in accordance with for the reactions involving Zwitter ions which supported the rate determining step in the proposed mechanism. 
Study of Oxidation of Some Alpha Amino Acids by 1,3-Dichloro-5, 5-Dimethylhydantoin in Aqueous Acetic Acid Medium

Table1. Effect of varying Amino Acid on the rate of reaction

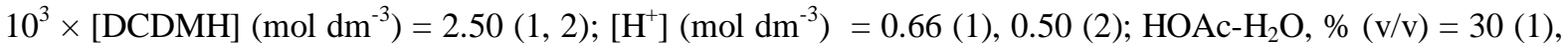
20 (2) ; Temp. $\mathrm{K}=303$ (1), 308 (2)

\begin{tabular}{|c|c|c|c|}
\hline \multirow[t]{2}{*}{ S. No. } & \multirow[t]{2}{*}{$10^{2} \times[$ Amino acid $]\left(\mathrm{mol} \mathrm{dm}^{-3}\right)$} & \multicolumn{2}{|c|}{$10^{4} \mathrm{k}_{\mathrm{obs}}\left(\mathrm{s}^{-1}\right)$} \\
\hline & & $\ell$-Alanine $\left(\mathrm{CH}_{3} \mathrm{CH} \mathrm{NH} \mathrm{NH}_{2} \mathrm{COOH}\right)(1)$ & $\ell$-Glycine $\left(\mathrm{NH}_{2} \mathrm{CH}_{2} \mathrm{COOH}\right)$ \\
\hline 1. & 0.50 & 1.43 & 1.95 \\
\hline 2. & 1.00 & 3.34 & 4.14 \\
\hline 3. & 1.25 & 3.92 & 4.75 \\
\hline 4. & 2.00 & 4.65 & 7.16 \\
\hline 5. & 2.50 & 7.33 & 8.91 \\
\hline
\end{tabular}

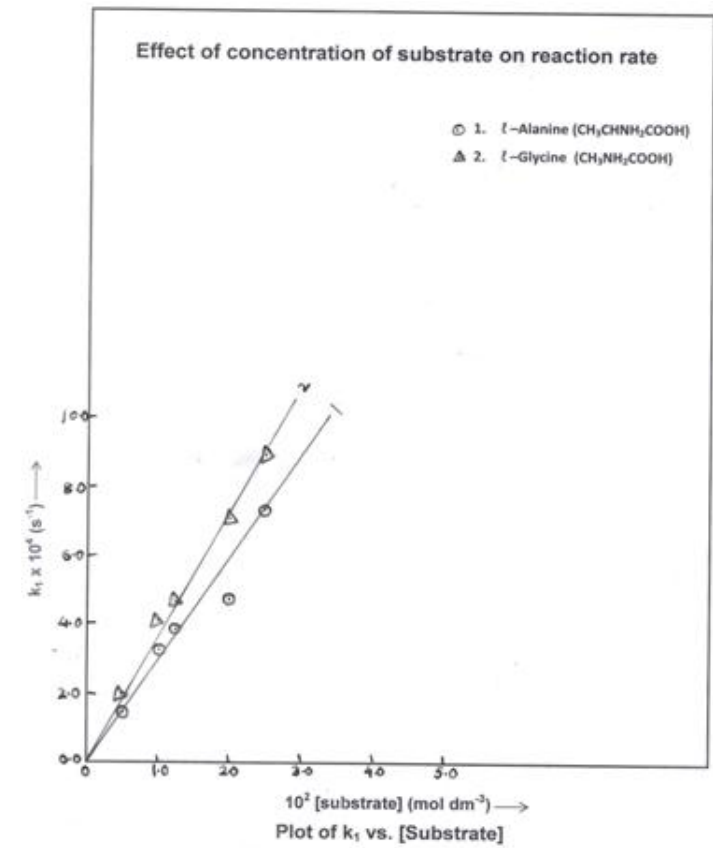

Fig1. 103[DCDMH] $(\mathrm{mol} \mathrm{dm}-3)=2.50(1,2) ;[\mathrm{H}+](\mathrm{mol} \mathrm{dm}-3)=0.66(1), 0.50(2) ; \mathrm{HOAc}-\mathrm{H} 2 \mathrm{O}, \%(\mathrm{~V} / \mathrm{V})=30$ (1), 20(2); Temp. $K=303(1), 308$ (2)

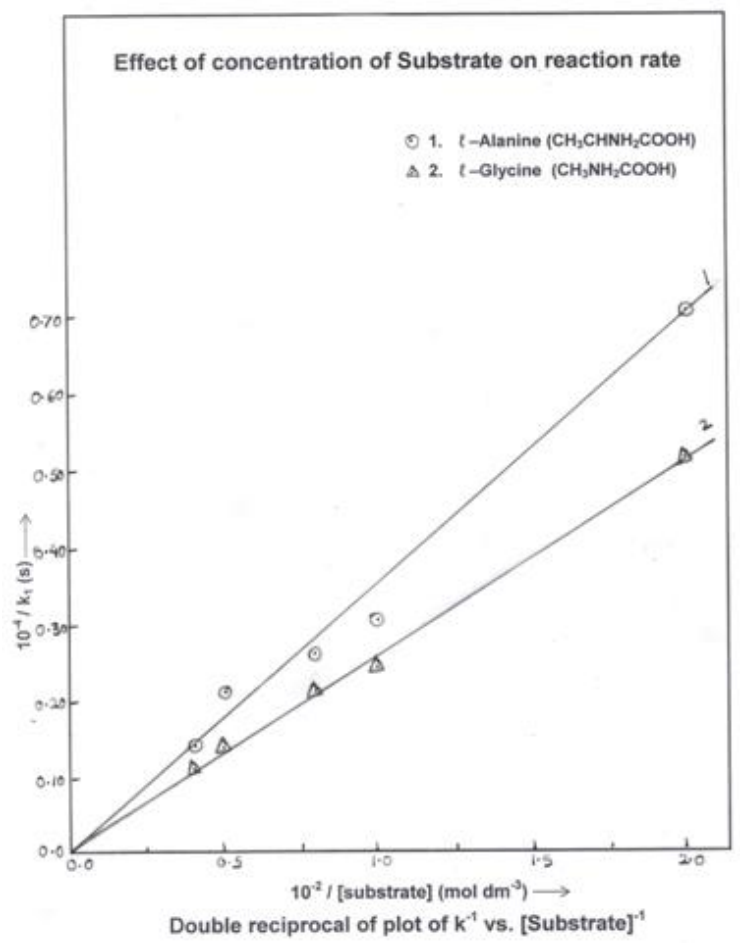

Fig2. $10^{3}[D C D M H]\left(\mathrm{mol} \mathrm{dm}^{-3}\right)=2.50(1,2) ;[\mathrm{H+}]\left(\mathrm{mol} \mathrm{dm}^{-3}\right)=0.66(1), 0.50(2) ; \mathrm{HOAc}-\mathrm{H}_{2} \mathrm{O}, \%(\mathrm{~V} / \mathrm{V})=30(1)$, 20 (2); Temp. $K=303(1), 308(2)$ 
Study of Oxidation of Some Alpha Amino Acids by 1,3-Dichloro-5, 5-Dimethylhydantoin in Aqueous Acetic Acid Medium

Table2. Effect of Dielectric constant of the medium on the rate of oxidation

$10^{2} \times\left[\right.$ Amino acid] $\left(\mathrm{mol} \mathrm{dm}{ }^{-3}\right)=2.0(1), 1.25(2) ; 10^{3} \times[$ DCDMH $]\left(\mathrm{mol} \mathrm{dm}{ }^{-3}\right)=2.50(1,2) ;\left[\mathrm{H}^{+}\right]\left(\mathrm{mol} \mathrm{dm}^{-3}\right)$ $=0.66(1), 0.50$ (2); Temp. $\mathrm{K}=303$ (1), 308 (2)

\begin{tabular}{|c|c|c|c|c|}
\hline \multirow[t]{2}{*}{ S. No. } & \multirow{2}{*}{$\begin{array}{c}\mathrm{HOAcH} \mathrm{H}_{2} \mathrm{O} \\
\%(\mathrm{v} / \mathrm{v})\end{array}$} & \multirow{2}{*}{$\frac{10^{3}}{\mathrm{D}^{*}}$} & \multicolumn{2}{|c|}{$\longleftrightarrow \quad 10^{4} \mathrm{k}_{1}\left(\mathrm{~s}^{-1}\right) \longrightarrow$} \\
\hline & & & $\begin{array}{c}\ell \text {-Alanine } \\
\left(\mathrm{CH}_{3} \mathrm{CH} \mathrm{NH} \mathrm{NH}_{2} \mathrm{COOH}\right) \\
(1)\end{array}$ & 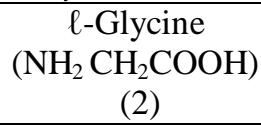 \\
\hline 1. & 10 & 15.50 & - & 4.28 \\
\hline 2. & 20 & 17.17 & 4.14 & 4.75 \\
\hline 3. & 30 & 19.15 & 4.65 & 5.16 \\
\hline 4. & 40 & 21.98 & 4.98 & 5.49 \\
\hline 5. & 50 & 25.64 & 5.40 & - \\
\hline
\end{tabular}

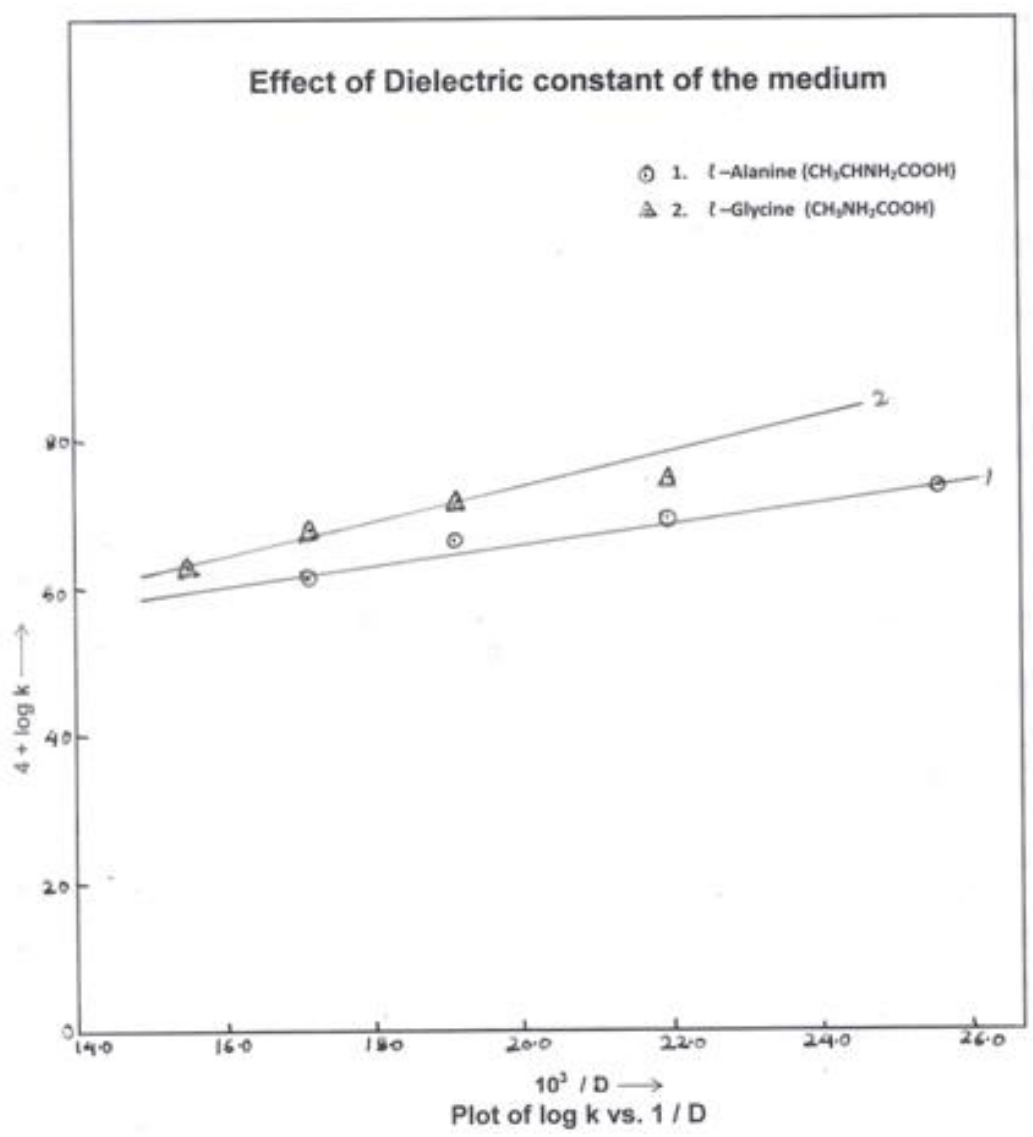

Fig3. $10^{2}\left[\right.$ Substrate] $\left(\mathrm{mol} \mathrm{dm} \mathrm{m}^{-3}\right)=2.0(1), 1.25(2) ; 10^{3}[\mathrm{DCDMH}]\left(\mathrm{mol} \mathrm{dm} \mathrm{m}^{-3}\right)=2.50(1,2) ;\left[\mathrm{H}^{+}\right]\left(\mathrm{mol} \mathrm{dm}^{-3}\right)=$ 0.66 (1), 0.50(2); $\mathrm{HOAc}-\mathrm{H}_{2} \mathrm{O}, \%(\mathrm{~V} / \mathrm{V})=30(1), 20(2)$; Temp $\mathrm{K}=303$ (1) 308 (2)

\section{REFERENCES}

[1] Patrocino, F.A.: J. Organomet. Chem., 2000, 603, 220b.

[2] Thenraja, D., Subramanian, P., and Srinivasen, C. : J. Chem. Soc., Perkin Trans., 2002, 2, 2125.

[3] Kolvari, E., Ghorbani-Choghamaranani, A., Salehi, P., Shirini, F., and Zolfigol, M.A. : J. Iran. Chem. Soc., 2007, 4, 126,

[4] Mohamed Farook, N.A., Seyed Dameem, Murugesan, A., and Kanagaraj, M. : E. Journal Chem., 2004, 132-136.

[5] Hawkins, C.L., and Davies, M.J.: Free Radical Bio. Med., 2005, 39, 1(2), 900.

[6] Kutti Rani, S., Eswaramurthy, D., Bilal, Mohamed, T., and Palanichaong, M.: Appl., Catal. A: General, 2009, 1-7, 369 (102).

[7] Katre, Y.R., Solanki, S.K. M., Sangeeta, P, and Joshi, G.K.: Asian J. Chem., 2005, 17, 423.

[8] Mahadevappa, D.S., Puttaswamy, and Made Gowda, N.M.: Proc. Indian Acad. Sci. (Chem. Sci.) 1988, 100(4),261, 
[9] Puttaswamy, and Vaz, N.: J. Indian Chem. Soc., 2004, 479, 81.

[10] Bisnoi, M.L., and Benerji, K.K.: J. Indian Chem. Soc., 1985, 41(24), 6049-6050.

[11] Vivekanandan, K., and Nambi, K.: J. Indian Chem. Soc., 1999, 76, 198-201.

[12] Malharrao, R., Thombare, and Gavisiddappa, S. Gokavi : J. Braz. Chem. Soc., 2014, 25, 1545-1551.

[13] Singh, A.K., Singh, V., Rahmani, S., and Singh, B.: J. Mol. Catal. A, 2003, 91, 197.

[14] Balasubramaniyan, P.V., and Mathiyalagan, N.: J. Chem. Pharm. Res., 2011, 522, 3.

[15] Vivekanandan, K. and Nambi, K: J. Indian Chem. Soc., 1999, 198.

[16] Tamil Selvi, P. and Karunakaran, K.: Asian J. Chem. 2016\5, 27(5), 1725-1728.

[17] Rao, Shan, and Dhannure, K.: Ph. D. Thesis, Nagarjuna University, India, 2003.

[18] Kumar, Anil J. and Nadar, A.: Bull. Korean Chem. Soc., 1999, 46A, 1792.

[19] Soni, Mamta, Khan, M.U., and Tiwari, R.K.: J. Chem. Tracks, 2012, 14(2), 415-418.

Citation: S. Neeraj et al., "Study of Oxidation of Some Alpha Amino Acids by 1, 3-Dichloro-5, 5Dimethylhydantoin in Aqueous Acetic Acid Medium", International Journal of Advanced Research in Chemical Science (IJARCS), vol. 5, no. 3, pp. 9-14, 2018. http://dx.doi.org/10.20431/2349-0403.0503002

Copyright: (c) 2018 Authors. This is an open-access article distributed under the terms of the Creative Commons Attribution License, which permits unrestricted use, distribution, and reproduction in any medium, provided the original author and source are credited. 